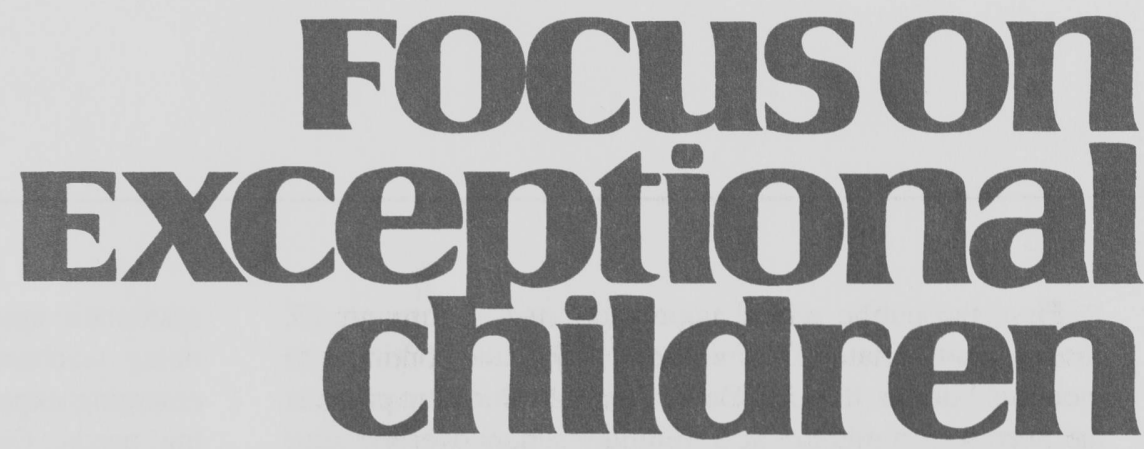

\title{
A National Assessment of Staff Development Needs Related to the Education of Students with Disabilities
}

\author{
Edward L. Meyen, Eugene Ramp, Cheryl A. Harrod, Yvonne N. Bui
}

Among the many factors that contribute to staff development needs for experienced teachers are IDEA compliance, curriculum standards, faculty turnover, high-stakes testing, and increased expectations among policymakers and school patrons. As teachers pursue personalized staff development plans, they seek opportunities to enhance their skills and expand their knowledge. Typically, if they are engaged in a graduate-degree program, they are likely to depend on their home institution of higher education (IHE) as the source for their professional growth experiences. If they are not pursuing a degree program, they may look to their employer to provide staff development opportunities or, on their own, seek opportunities that best fit their needs and aspirations.

With the emergence of the Internet access to professional development opportunities is increasing at an unprecedented rate. Offerings by IHEs on the Internet are increasing, professional associations are developing web sites to offer staff development, and e-learning in the commercial sector is evolving as a source for staff development. Thus, the Internet has dramatically changed the potential for accessing staff development anytime, anywhere.

The need for staff development among teachers to fully implement the Individuals with Disabilities Education Act (IDEA) is exacerbated by the growing shortage of trained personnel and the tendency for states to allow emergency waivers for noncertified teachers to enter the field when the supply of certified teachers does not meet the demand. In particular, educators trained to work with students with disabilities continue to be in short supply (Brownell \& Smith, 1993, Brownell, Smith, McNellis, \& Miller, 1997); Lauritzen \& Freidman, 1993), a shortage that is expected to become even more acute in coming years, for several reasons.

Edward L. Meyen is Director of the On-Line Academy, a Center for Research on Learning project, and co-director of the e-Learning Design Lab at the University of Kansas. Eugene Ramp was with the e-Learning Design Lab when the study was conducted. Cheryl Harrold is with the e-Learning Design Lab at the University of Kansas. Yvonne Bui is with the Department of Learning and Instruction at the University of San Francisco. 
First, the public school population, ages 5 through 13, rose to approximately 38.5 million in 1998 and continues to increase. Further, the U.S. Department of Education projects the need for an additional 2 million teachers over the next decade as veteran teachers (i.e., the baby boom generation) retire. This critical personnel shortage is particularly significant when considering the chronic shortage of special education teachers over the past decade.For example, the Twentieth Annual Report to Congress on the Implementation of the Individuals with Disabilities Education Act (1998) reports that from 1987-88 to 1995-96, shortages for teaching positions nationally for students aged 6-21 with disabilities have averaged about 27,000 fully certified teachers per year. The training of new teachers is inadequate to meet projected personnel needs. This means that large numbers of teachers will enter the profession with significant staff development needs.

The logic for employing online technologies as a major option for delivering staff development evolves from the context surrounding the national need for staff development by teachers. This need has grown as a consequence of legislation such as No Child Left Behind (NCLB). Without a

\section{Focuson
Exceptional children}

ISSN 0015-511X FOCUS ON EXCEPTIONAL CHILDREN (USPS 203-360) is published monthly except June, July, and August as a service to teachers, special educators, curriculum specialists, administrators, and those concerned with the special education of exceptional children. This publication is annotated and indexed by the ERIC Clearinghouse on Handicapped and Gifted children for publication in the monthly Current Index to Journals in Education (CIJE) and the quarterly index, Exceptional Children Education Resources (ECER). The full text of Focus on Exceptional Children is also available in the electronic versions of the Education Index. It is also available in microfilm from Xerox University Microfilms, Ann Arbor, MI. Subscription rates: Individual, \$36 per year; institutions, $\$ 48$ per year. Copyright (C) 2003, Love Publishing Company. All rights reserved. Reproduction in whole or part without written permission is prohibited. Printed in the United States of America. Periodical postage is paid at Denver, Colorado. POSTMASTER: Send address changes to:

Love Publishing Company

Executive and Editorial Office

P.O. Box 22353

Denver, Colorado 80222

Telephone (303) 221-7333

Karen Harris

University of Maryland
Thomas Skrtic University of Kansas

James Shriner University of Illinois

Erica J. Lawrence Editor
Stanley F. Love Publisher systematic approach to staff development nationally, practicing teachers are unlikely to be prepared to meet the emerging expectations for students with exceptional learning needs. Online technologies provide the capacity to enhance the efforts of states and districts in addressing these needs. The staff-development needs of teachers related to improving performance outcomes for students with exceptional learning requires a major investment in creating staff development initiatives that can be taken to scale. Online technologies offer that potential.

\section{FEATURES AND ADVANTAGES OF ONLINE STAFF DEVELOPMENT}

Features of online staff development that illustrate what makes online staff development available as options are:

- $24 / 7$ access

- National dissemination

- Content experts involved in development

- Rapid response time

- Revision capabilities

- Accountability

Clearly, the ability to go to scale national distribution and $24 / 7$ access are important features, as they help to ensure that teachers will have access to the opportunity for professional development at times that are most convenient to them. Because all content must be in final form when posting to online technologies, especially those of an asynchronous nature, the content can be reviewed, and juried if necessary. This adds a measure of accountability that is not as easily achieved in other forms of staff development. Once revised, the changes can be made available nationally, which quickly adds to the strength of this option for staff development.

Some advantages of online staff development that contribute to this model for delivering staff development warrant special consideration when making decisions regarding the use of online technologies for staff development. Advantages of the self-paced nature of online staff development cannot be overestimated. Teachers maintain busy professional schedules and usually have significant demands on their time. This complicates the probability that their schedules will match a rigid schedule for participating in staff development.

Allowing teachers more control of their engagement in staff development is important. Being able to preview what is to be covered in advance is important to them, too, in making decisions as to the appropriateness of the content for them personally. Most states have a system whereby teachers maintain some accounting of their staff development experiences in a portfolio. Online instructional technologies 
enable them the ability to produce detailed accounts of the content, as well as evidence, of their performance.

In short, advantages of online staff development are:

- It is self-paced.

- It is teacher-controlled.

- It is convenient to participate.

- It allows for public review.

- It is personalized.

- It provides for portfolio management.

- It enables sharing of resources.

\section{BACKGROUND}

In response to the growing need for staff development of teachers, OSEP contracted with the Online Academy(http: //onlineacademy.org) to develop a series of exemplary online modules for staff development on topics of high national concern. The online format would allow for experimentation with online instruction as a mode of delivering staff development. The modules would be designed using the production tool developed by the Online Academy to produce multimedia interactive online modules. The modules should be content-rich, self-paced, accessible 24-7, employ streaming media, be interactive, and have a research-to-practice focus.

A prerequisite to developing online modules was to identify which topics were representative of nationally perceived needs. It was apparent that if only five online modules were to be developed (a limitation of resources), it was essential to select topics of national importance. Although the five topics could have been selected by consulting with a few staff development specialists at the state and national levels, a decision was made to systematically examine the need for staff development nationwide. This would this result in better decisions on the topics, and having an inventory of assessed staff development needs would be useful to SEAs and LEAs in planning staff development programs in the future. In addition, such an inventory might have implications for preservice teacher education programs. Finally, professional organizations, publishers of teaching resources, and individuals engaged in developing staff development programs would find the inventory to be of interest.

\section{METHODOLOGY}

The first challenge was to determine an appropriate method for prioritizing staff development needs nationally as a basis for identifying the topics for the staff-development modules to be developed. Several examples of needs-assessment strategies have been employed at the state level. For example, Azin-Manley (1996) used a survey instrument to obtain input from all teachers and administrators in
Wyoming schools. In another survey, the Illinois State Board of Education (1992) carried out a statewide needs assessment for personnel associated with prekindergarten programs for children at risk of academic failure, prevention initiative programs for at-risk infants and toddlers and their families, and the model early childhood parental training programs.

A similar model could have been used to assess the staffdevelopment needs of teachers nationally in meeting the needs of students with disabilities. The problem in adopting this strategy for a national needs assessment, however, was to determine the most representative sampling, as well as cost and time requirements.

Two other statewide strategies were considered:

1. A model implemented by Black (1998) surveyed all directors of technical and adult education within a state who attended a conference. The results were supplemented by a mail survey of all instructors statewide.

2. Taking another approach, Hart (1995) reported on the use of focus groups to collect qualitative data on staff development needs.

The advantages of focus groups are that data can be collected in a relatively brief time, and the results can be combined with other measurement methods. Focus groups also serve to improve communication and allow for clarification on recommended topics.

Based on these findings, we opted to develop a hybrid model that employed focus groups, engagement of key state agency staff members attending a national conference, and an online ranking system to build a set of national priorities in staff development to guide the initial development of online staff development modules.

\section{Advisory Board}

Working with the leadership of OSEP and the National Association of State Directors of Special Education (NASDSE), a national advisory board was assembled, composed of State Education Agencies (SEA), CSPD (Comprehensive System of Personnel Development), State Improvement Grants (SIG), Regional Resource Centers (RRC), and National Association of State Directors of Special Education (NASDSE) personnel. The advisory board included 10 carefully selected individuals with expertise in staff development, as well as professionals from the Monitoring and State Improvement Planning Division and the Research to Practice Division of OSEP. This board served a central role throughout the topic-identification process and continued to provide significant input during the module development stages. 
A qualitative approach, relying heavily on focus groups involving resource experts, was adopted, combined with an analysis of source documents containing information related to staff development needs, a phone survey, and an online prioritization instrument.

\section{Focus Groups}

Four focus groups were held to generate staff development topics perceived by the participants as representing national concerns and warranting an investment at the national level. Each focus group session lasted approximately 60 minutes.

One group session consisted of 15 OSEP staff members from the divisions of Research to Practice and Monitoring and State Improvement Planning. Each participating staff member had the responsibility for monitoring state implementation of IDEA, providing them perspectives on staff development needs. This session was held in the Monitoring and State Improvement Plan Division (MSIPD) offices.

Two focus groups were held at the CSPD 2000 national conference. Participants recommended by the staffs of NASDSE and OSEP as knowledgeable about national staff development needs were invited and assigned to focus groups in advance of the conference.

The fourth focus group was made up the 10-member national advisory board. Because members of the board were selected on the basis of their perspectives on staff development and knowledge of state needs, their input was considered important to have factored into the topic-identification process.

The focus group membership and process are as follows:

1, The number of participants per group averaged 13 .

2. The focus groups were held in the OSEP offices and during the 2000 CSPD Conference sponsored by NASDSE.

3. The same facilitators and recorder (a three-person team from the Academy) were involved in each focus group. Two functioned as facilitators and assumed the role of stimulating discussion and keeping the discussion focused on generating and clarifying topics. The third person recorded the topics emerging from the discussion on which there was group consensus.

4. Immediately following each session, the three-person team refined the list of topics and sorted them into categories. Independent summary reports were prepared for each session, but the reports were not shared with participants in subsequent sessions prior to their session. This allowed each group to be independent in generating topics.

5. Following the first focus group, the team repeated the refinement process for each session. Specifically, the categories derived from the first session were reconstructed after each session as the topics generated in each session were factored into the sorting process. Consequently, as the number of topics grew, the categories changed depending on the emphasis of the topics added to the pool from the previous session.

6. An inventory of staff development topics was created based on the consensus topics emerging from the groups.

7. Following the last focus group, a final refinement and sorting process was employed. The last group consisted of the 10-member advisory board, whose composition was similar, in terms of expertise, to that of the other focus groups. Having the advisory board serve as a focus group enhanced the members' later role in working with consultants and content writers.

\section{Phone Survey and Review of Source Document}

The phone survey and review component consisted of the following:

1. A firm that provides evaluation studies was engaged to conduct a phone survey and to review SIG proposals and selected reports on staff development in the literature.

2. The phone survey consisted of a sample of more than 25 individuals nationally, including general education teachers and school administrators. The phone survey and literature review were carried out parallel to the focus groups and were completed at the same time.

3. A series of stimulus questions was used to cause respondents to think about staff-development needs.

4. The Study Group Inc. prepared a report independent of the focus group report process. The report results were not made known to the Academy team of facilitators until the results of the focus group and the validation process were completed. This allowed the survey data to be factored into the prioritization process as an independent source of input.

\section{Validation Process}

The validation process allowed all participants across the focus groups to respond to an instrument containing all topics generated via the focus group process. The specific steps of the process are outlined below.

1. The Academy team analyzed the combined results of the focus groups and eliminated redundancies.

2. An instrument containing nine subsets and 113 topics was developed. A subset was defined as topics related to a theme or similar in terms of the training implied. No topic was assigned to more than one 
subset. The number of topics per subset ranged from four to 22 .

3. The instrument was posted on the project web site, and all responses were collected online. Respondents were notified of the URL, provided directions on the task that they were being asked to perform-that is, to prioritize each topic by placing it into one of four categories (see Table 1, at the end of this article) and given a timeline for responding.

4. The data were analyzed by ranking the topics according to the categories in which the respondents placed them. Topics then were judged to be of national, state, and local significance.

5. Results of the phone survey and the literature review were analyzed to determine the relationship between the topics identified through those processes and the focus groups. They then were crosschecked against the results of the categorizing process that was carried out online. For purposes of selecting the five topics to be developed into online staff development modules, these data were recorded, along with the instrument categorizing results.

6. Anticipating that a substantial number of topics might be classified as being of national significance and warranting being addressed through a national effort, a set of decision rules for selecting topics for module development was developed by the Academy team in conjunction with the advisory board. These decision rules were used as a criteria for selecting the topics for module development from among those judged to be of most importance nationally. The selection criteria were decided during an advisory board meeting.

In decision rules employed by the board, the topics must:

1. Be research-based or highly validated.(This was consistent with the mission of the Online Academy.)

2. Entail content and instructional goals that can be incorporated effectively within the Academy module design. The Academy module design had been validated already. Thus, incorporation was important, to capitalize on the investment already made in the technology and to expedite the development process within the designated timeline.

3. Require content and activities to effectively cover the information and skills central to the topic within the limitations of a three- or four-lesson module (about 12 clock hours of instruction).

4. Accommodate a range of needs that transcend grade level and disability groups, and that relate to the requirements of IDEA.
5. Have been proposed as a need area from several input sources rather than a single source.

6. Have a high probability of being successfully addressed through staff development efforts, and be valued by the target group.

A major limitation of the study was that it focused on school-age programs and did not include early childhood staff-development needs. Further, in the process of selecting topics, the board opted to orient the modules toward teachers at the secondary level. Comments throughout the forum sessions indicated that staff development was needed at the secondary level and fewer resources were available. The topics, however, were applicable for the $\mathrm{K}-12$ programs unless specifically addressed to an age group.

\section{RESULTS}

Results of the prioritization responses to the instrument are shown in Table 1, at the end of the article. The number of responses per category are reported in the four columns on the righthand side of the table. In reviewing the results in Table 1, keep in mind that the purpose was to identify topics of national significance that warranted an investment into creating online development resources for national dissemination.

The categories were defined as follows:

Category 1: National Response (High Priority): Should be addressed nationally and in the immediate future.(Use this category for no more than 10 of the topics listed in the next pages.)

Category 2: National Response (Medium Priority): Very important, but if a choice had to be made to develop a priority, the Category 1 topics would be selected.

Category 3: State Response: Important priority, but a topic that could be addressed at the state level rather than through a national initiative.

Category 4: Local Response: An important topic warranting attention at the LEA level. May require SEA leadership, but represents a topic that can and should be addressed at the LEA level.

Items with asterisks in Table 1 indicate that the topics were selected for development into online modules after applying the decision rules previously mentioned. Because the topics were not all independent - that is, many overlapped when viewed from the perspective of how they might be dealt with through a staff development program-framing the topics selected for module development varied somewhat from the wording listed on the survey instrument. 
Clarification of the topics occurred through a 2-day planning session involving the board, Academy team, and consultants with expertise in the skills and knowledge associated with the high-priority topics. The intent here was to translate the selected topics into wording content maps that were more meaningful to teachers.

The process entailed a review of the ranked topics in the four categories to ensure that there were no topics in Categories 2, 3, or 4 that, when examined by the Advisory Board and consultants, might be viewed as warranting special consideration. Because the membership of the board and consultants included individuals with extensive knowledge of states, staff development programs, and IDEA, their perspectives provided a validation of the ranking system.

Although this review did not result in any topics being moved to Category 1, it did stimulate discussion on two issues.

1. The omission of early childhood in the needs assessment process.

2. The focus on topics most important to middle and secondary schools.

Participants agreed that if further staff development modules are developed in the future, preschool needs should be included in the assessment process. With reference to the middle- and secondary-school emphasis, it was decided, in reviewing the Category 1 priority rankings, that the general need for staff development was greater at those levels. This is not to suggest that the topics do not generalize to teachers at the elementary level. Consequently, once the priority topics were selected from Category 1, they were analyzed in terms of their application to the middle- and secondaryschool levels.

Once the topics were selected, content maps in the form of outlines were developed as a way of operationally defining the topics. This was considered important prior to engaging writers to develop content for the modules.

Following are the topics selected for development in the form of online modules.

1. Curricular design and instructional accommodations for secondary students with mild disabilities.

2. Relating instructional assessments to standards.

3. Models for collaboration.

4. Transition-focused secondary education for all students.

5. Developing standards-based IEPs.

\section{SUMMARY OF LESSONS LEARNED}

1. The use of focus groups proved to be an effective strategy for developing an item pool of staff-development needs and topics of national importance.
Considerable overlap occurred across focus groups. The topics that surfaced most frequently were the ones ultimately ranked in the national response category in the prioritization process via the online instrument.

2. Use of the Web to obtain responses to a validation and prioritizing instrument was effective with a sample of respondents with vested interests in the results. This was not a random sample. All respondents had been involved in some aspect of generating items or were participating in the project.

3. Consensus can be achieved on staff development topics warranting attention at the national level. Although the language may vary for how best to describe each topic, groups with national perspectives share common views on staff development needs when judged by categories of priority needs.

4. Needs specific to curriculum content or subject-matter fields did not receive significant attention in the needs-assessment process because the Academy had already addressed may of them in previously developed online modules in reading, positive behavioral support (PSB), and technology in education. A process that engages teachers rather than staff development specialists and experts in national roles might result in more curriculum/instruction related topics.

5. The high-priority topics derived largely from the consequences of reauthorization of IDEA.

6. Focus group participants had serious concerns about staff-development issues. The level of discourse was consistent, and each session could have gone beyond the scheduled timeframe.

7. There seemed to be a close relationship between the perspectives of OSEP staff members who participated in the first focus group and SEA and RRC representatives participating in subsequent focus sessions.

8. The need for staff development for teachers is of critical importance. Participants in the focus groups had a clear perception that a major investment has to be made in models that allow for national dissemination, represented by the features allowed by online instruction.

9. The topics in Table 1 reflect skills and knowledge that teachers need and which warrant serious attention in preservice teacher education. Additional research needs to be done to ascertain the extent to which preservice curriculum covers the topics judged to be high priority staff-development needs for practicing teachers. 


\section{TABLE 1}

\section{Staff Development Topics Sorted by Priority Categories}

Category 1: National Response (High Priority): Should be addressed nationally and in the immediate future.

Category 2: National Response (Medium Priority): Very important, but if a choice had to be made to develop a priority, the Category 1 topics would be selected.

Category 3: State Response: Important priority, but a topic that could be addressed at the state level rather than through a national initiative.

Category 4: Local Response: An important topic warranting attention at the LEA level. May require SEA leadership, but represents a topic that can and should be addressed at the LEA level.

Rank

Order Topic

Best practices on curriculum/instructional accommodation*

Relating instructional assessments to standards*

Bilingual teaching practices that work

Modifying curriculum to the needs of students with mild to

moderate disabilities

Models for collaboration*

What constitutes an effective transition plan?*

Accommodation--special and general education teachers

working together

8 Developing standards based IEPs*

9 Understanding alternative assessments

10 Assessing progress of students with disabilities in the general

curriculum

11 The teacher's role in collaboration

12 Understanding national curriculum standards

13 Issues related to measuring student progress

14 Defining outcomes for transition

15 Achieving accommodation in high-stakes testing states

16 Collaboration skills and accessing the general curriculum

17 Understanding cultural differences in teaching English

18 School-wide behavior management planning processes that work

19 Creating standards based IEPs

20 Collaborating with general classroom teachers

21 Mentoring paraprofessionals

22 Sound pedagogical practices

Planning instructional systems that build from a philosophy of school improvement, curriculum frameworks, standards and IEP planning

Working with families of non-English-speaking children

Techniques for monitoring student progress on IEPs

Measuring progress in achieving the IEP

Efficient and effective approaches to accommodation

Collaboration skills for teachers at the secondary level

Category 
TABLE 1 (continued)

Rank

Order Topic

Category

31 Standards based reform strategies for special and general

education teachers to work together

32

Setting outcomes for middle school students

Classroom discipline strategies

Developing behavior plans

Techniques applicable to instructional differentiation

The use of financial assessment in IEP planning

Strategies for developing transition plans for students with mild

disabilities

Understanding critical education in the general education curriculum

How to design informal assessments that align with standards

based testing

Coordinating services across agencies for families and children

(target could be service coordinators across disciplines)

Knowing what accommodations to ask for in general education

Curriculum accommodation strategies that generalize across content areas

Inclusion skills for beginning classroom teachers

Accommodation strategies

Collaborative strategies applicable to sharing behavior management techniques

Relating national curriculum standards to state standards

Tracking assessments to IEP goals

Working with families of children 0-2 and 3-5 programs

Working with paraprofessionals

Adapting instructional plans

Collaborating with parents

Translating curriculum standards by subjects to meet the needs of student with disabilities

Co-teaching techniques applicable to achieving accommodations

Accommodating the needs of students with sensory disabilities in a standards-based curriculum

Teaming at the building level

Understanding the basics of bilingual education and English as a

Second Language

Behavior management strategies applicable to $0-3$ and 3-5 year olds

Basic collaboration skills

Strategies beyond PBS

Aligning standards-based curriculum with needs of students in inclusion settings

$2 \quad 1+2 \quad 3 \quad 4$

Creating assessments in forms that allow students with disabilities

to gain routine experience with those formats and testing procedures used in statewide testing programs

\begin{tabular}{|c|c|c|}
\hline 4 & 9 & 4 \\
\hline 3 & 8 & 4 \\
\hline 3 & 8 & 4 \\
\hline 2 & 7 & 7 \\
\hline 8 & 12 & 1 \\
\hline 8 & 12 & 5 \\
\hline 7 & 11 & 4 \\
\hline 6 & 10 & 6 \\
\hline 6 & 10 & 7 \\
\hline 6 & 10 & 7 \\
\hline 5 & 9 & 3 \\
\hline 5 & 9 & 3 \\
\hline 5 & 9 & 8 \\
\hline 5 & 9 & 6 \\
\hline 5 & 9 & 7 \\
\hline 5 & 9 & 9 \\
\hline 5 & 9 & 6 \\
\hline 5 & 9 & 3 \\
\hline 5 & 9 & 4 \\
\hline 4 & 8 & 6 \\
\hline 4 & 8 & 1 \\
\hline 4 & 8 & 6 \\
\hline 3 & 7 & 7 \\
\hline 3 & 7 & 9 \\
\hline 3 & 7 & 7 \\
\hline 8 & 11 & 5 \\
\hline 7 & 10 & 6 \\
\hline 6 & 9 & 6 \\
\hline 6 & 9 & 4 \\
\hline 6 & 9 & 7 \\
\hline 6 & 9 & 5 \\
\hline 5 & 8 & 7 \\
\hline 5 & 8 & 8 \\
\hline
\end{tabular}


TABLE 1 (continued)

\begin{tabular}{llllll} 
& Rank & \multicolumn{4}{c}{ Category } \\
\cline { 3 - 6 } Order Topic & 2 & $1+2$ & 3 & 4 \\
\hline
\end{tabular}

64 Role of the general education teacher on the IEP team

65 (e.g., documentation)

65 Conflict resolution strategies that work

66 Making effective use of adults in the instructional environment

67 Time-management strategies for collaboration

68 Preparing 14-year-olds as self-advocates in the IEP process

69 Assessment-based instruction

70 Understanding age-appropriate content in the general education curriculum

Using informal assessment as a basis for instructional planning Getting a job is not enough

Communicating with parents of students with disabilities

Mediation skills for teachers

Engaging general classroom teachers in the IEP process

Working with families and parents in supporting students in

inclusion programs

Building community with colleagues

78 Curriculum planning for teachers: neither texts nor tests equal curriculum

Understanding transition requirements (0-2, 3-5, and secondary)

80 Teaming strategies in ESL

81 Developing behavior modification plans and strategies for measuring progress

Strategies for instructional planning based on curriculum standards Teaching reading across the content fields

Teaching the language of the subject (e.g., in science and math there is a critical vocabulary that must be known to participate in the general curriculum)

\section{Effective ECH transition practices}

Techniques for handling conflict resolution

Transitional opportunities in rural areas

Involving community agencies in transitioning for 0-3 and

3-5 year olds

$\begin{array}{rrrr}5 & 8 & 6 & 4 \\ 4 & 7 & 3 & 2 \\ 3 & 6 & 5 & 6 \\ 3 & 6 & 6 & 6 \\ 1 & 4 & 9 & 5 \\ 9 & 11 & 7 & 2 \\ & & & \\ 8 & 10 & 4 & 4 \\ 8 & 10 & 4 & 4 \\ 6 & 8 & 4 & 6 \\ 5 & 7 & 6 & 5 \\ 5 & 7 & 3 & 3 \\ 5 & 7 & 8 & 3 \\ & & & \\ 5 & 7 & 6 & 3 \\ 5 & 7 & 6 & 7 \\ & & & \\ 5 & 7 & 7 & 4 \\ 5 & 7 & 8 & 3 \\ 4 & 6 & 9 & 3 \\ & & & \\ 4 & 6 & 4 & 8 \\ 4 & 6 & 9 & 3 \\ 4 & 6 & 10 & 2\end{array}$

Developing collaboration between teachers and related service providers

Role of paraprofessional classrooms serving non-English

speaking children

The basics of curriculum

Interpreting informal assessment results

Decision making in manifestation meetings

Self-advocacy for 14-year-olds

How to help students participate effectively as self-advocates

Measuring curriculum standards for classroom instructors

Different ways to collaborate

$\begin{array}{rrr}6 & 8 & 4 \\ 6 & 6 & 5 \\ 5 & 7 & 5 \\ 5 & 8 & 4 \\ 5 & 9 & 4 \\ 5 & 8 & 5 \\ & & \\ 5 & 8 & 4 \\ 4 & 13 & 1 \\ 9 & 4 & 4 \\ 8 & 0 & 4 \\ 8 & 6 & 4 \\ 8 & 4 & 6 \\ 7 & 4 & 7 \\ 6 & 5 & 5 \\ 6 & 6 & 5\end{array}$


TABLE 1 (continued)

\begin{tabular}{|c|c|c|c|c|c|}
\hline \multirow{2}{*}{$\begin{array}{l}\text { Rank } \\
\text { Order }\end{array}$} & \multirow[b]{2}{*}{ Topic } & \multicolumn{4}{|c|}{ Category } \\
\hline & & 2 & $1+2$ & 3 & 4 \\
\hline 99 & Transitional opportunities in urban settings & 5 & 6 & 8 & 4 \\
\hline 100 & Informal assessments: design, application, and interpretation & 5 & 6 & 7 & 4 \\
\hline 101 & Understanding the child's perspective in transitioning & 5 & 6 & 7 & 3 \\
\hline 102 & Monitoring the work of paraprofessionals & 4 & 5 & 6 & 7 \\
\hline 103 & Involving directors, counselors, teachers, and other care providers & 4 & 5 & 8 & 4 \\
\hline 104 & Teaming for solutions & 3 & 4 & 6 & 7 \\
\hline 105 & Student procedures for paraprofessionals & 3 & 4 & 7 & 6 \\
\hline 106 & Strategies for co-teaching with paraprofessionals & 2 & 3 & 6 & 7 \\
\hline 107 & How to design teacher-made tests & 6 & 6 & 8 & 4 \\
\hline 108 & Communities for transition for school programs. & 6 & 6 & 4 & 7 \\
\hline 109 & $\begin{array}{l}\text { Integrating related services into the general classroom instructional } \\
\text { program }\end{array}$ & 5 & 5 & 8 & 4 \\
\hline 110 & $\begin{array}{l}\text { Family role needs to be strengthened in IEP/teaching literacy } \\
\text { development for deaf and blind }\end{array}$ & 5 & 5 & 4 & 3 \\
\hline 111 & $\begin{array}{l}\text { Ensuring that paraprofessionals know their children understand } \\
\text { their role }\end{array}$ & 5 & 5 & 8 & 5 \\
\hline 112 & Transition strategies for hospital to home or to another care provider & 5 & 5 & 10 & 2 \\
\hline 113 & Focusing on speech and language in the general classroom & 2 & 2 & 9 & 6 \\
\hline
\end{tabular}

${ }^{\text {TTopics selected for module development }}$

\section{REFERENCES}

Azin-Manley, M. (1996). Staff development needs assessment survey. Cheyenne, Wyoming State Dept. of Education, Center for School Improvement, Region V, Board of Cooperative Educational Services.

Black, E.D. (1998). Staff development baseline needs assessment. [Analysis of a statewide survey of directors and full-time instructors]. Atlanta: Georgia Institute of Technology,

Brownell, M. T., \& Smith, S. (1993). Understanding special education teacher attrition: A conceptual model and implications for teacher educators. Teacher Education and Special Education, 16(3), 270-282.

Brownell, M. T., Smith, S. W., McNellis, J. R., \& Miller, M. D. (1997). Attrition in special education: Why teachers leave the classroom and where they go. Exceptionality, 7, 143-155.
Hart, E. (1995). The role of focus groups with other performance measurement methods. Paper presented at Northumbria International Conference on Performance Measurement in Libraries and Information Services, Huddersfield University Library, England, Available ERIC: ED 405884.

Illinois State Board of Education (1992). Results of the statewide staff development needs assessment for personnel associated with [the] Pre-kindergarten Program for Children at Risk of Academic Failure, [the] Prevention Initiative Programs for At Risk Infants and Toddlers and Their Families, [and the] Model Early Childhood Parental Training Programs. Springfield, IL: Author.

Lauritzen, P., \& Friedman, S. J. (1993). Meeting_the supply/demand requirements of the Individuals with Disabilities Education Act. Teacher Education and Special Education, 16(3), 221-229.

Preparation of this article was supported in part by the Office of Special Education Programs and Grant \#HO29K73002. We acknowledge the contributions of the Online Academy staff, the individuals who served on the various advisory boards, jurors and the many institutions, and individuals who contributed to the evaluation of the online modules and the production tool.Appreciation is expressed to the Center for Research on Learning and the Information \& Telecommunications Technology Center whose collaboration created the e-Learning Design Lab in which this work is being conducted. 


\title{
Curriculum Planning and Instructional Design for Gifted Learners
}

\author{
Joyce VanTassel-Baska
}

This comprehensive text establishes an exciting curriculum design model that caters to the unique needs of the gifted learner. While giving careful consideration to the current climate of educational reform, the text is able to preserve and enhance the important enterprise of gifted education.

The author's extensive experience in the field of gifted education makes this text an invaluable resource for students and teachers alike. Impressive in scope, the text gives thorough attention to crucial issues such as effective curriculum delivery, implementation strategies, and learner-outcome assessment.

Curriculum goals, learner outcomes, teacher-learning activities, instructional strategy design and selection, and management activities are among the important topics addressed in the individual chapters. The latter part of the book contains specific helpful sample curriculum units that exemplify strategies described throughout the book.

\section{SPECIAL FEATURES}

- Provides a comprehensive framework for curriculum planning.

- Designs an effective planning model for instruction.

- Outlines specific instructional strategies and curriculum units.

- Presents guidelines for learning assessment and curriculum evaluation.

\section{CONTENTS}

1 Introduction

2. Research on Curriculum Models in Gifted Education

3. Standards of Learning and Gifted Documents

4. Developing System-Wide Curriculum Documents

5. The Nature and Curriculum Needs of Gifted Learners

6. Developing a Philosophy and Goals for a Gifted Program

7. Developing Learner Outcomes

8. Designing Activities and Selecting Resources

9. Selecting Instructional Strategies

10. Employing Appropriate Curriculum Management Strategies

11. Implementing Curricula for the Gifted

12. Assessment of Learning and Evaluation of Curriculum

13. Toward Coherent Curriculum Policy in Gifted Education Appendix: Sample Curriculum Units 


\section{Professional update}

\section{World Council for Gifted and Talented Children}

August 1-5, 2003

Adelaide, South Australia

Contact: www.worldgifted.com

\section{Division for Learning Disabilities} Council for Exceptional Children

November 7-8, 2003

Nashville, Tennessee

Contact: www.TeachingLD.org

\section{TASH Conference}

December 10-13, 2003

Chicago, Illinois

Contact: www.tash.org

\section{Council for Exceptional Children}

April 14-17, 2004

New Orleans, Louisiana

Contact: www.cec.sped.org 